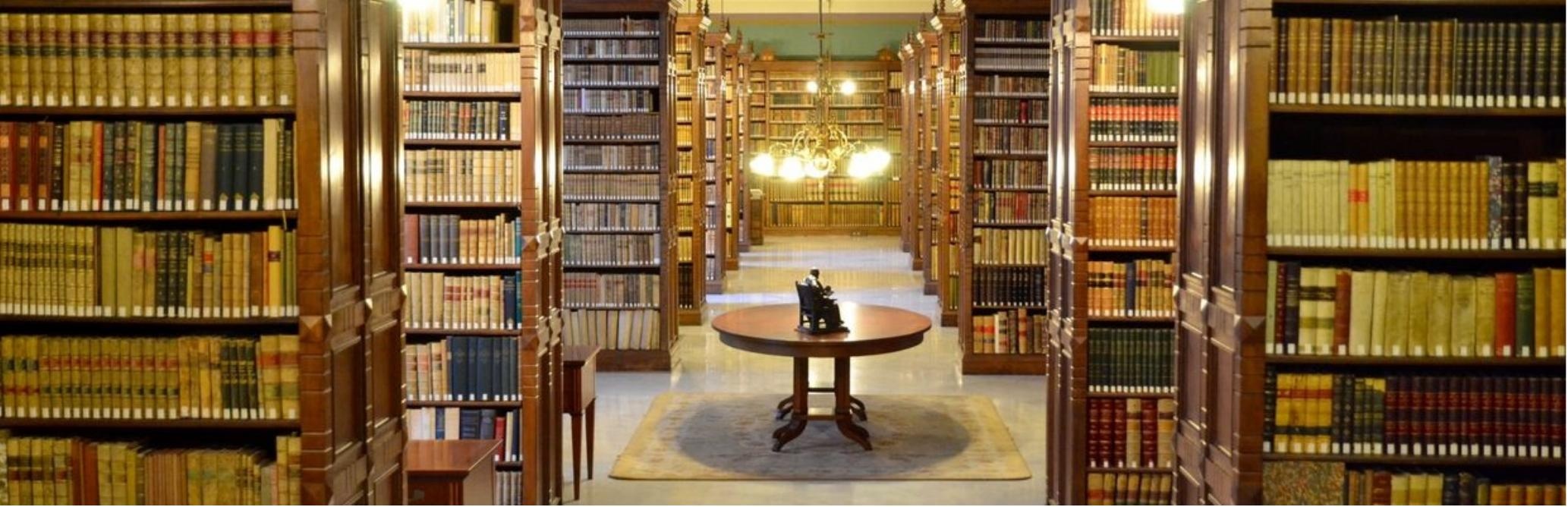

\title{
Editorial Volume 6, Issue 2
}

\author{
Authors: María Fernanda Sandoval \\ Submitted: $\quad$ 2. March 2019 \\ Published: $\quad$ 3. March 2019 \\ Volume: 6 \\ Issue: 2 \\ Affiliation: $\quad$ IASHA e.V., Freiburg, Germany \\ Keywords: $\quad$ Editorial, Josha Journal, 2019, February \\ Categories: News and Views \\ DOI: $\quad$ 10.17160/josha.6.2.543
}

Abstract:

New in JOSHA: Publication statistics, more information, exceptional papers. This year 2019 was wonderful as far as the purpose of our magazine is concerned. We were working together making visits to Schmelzeisen in Freiburg, Germany and preparing some changes in the Website. As you may have seen, now our readers are able to see the statistics with the exact number of views and downloads of every article. Moreover, we have added three buttons on the right side of the Homepage, so you can get an option to visit our links directly to the upcoming events, to our prizes, and also see how you can become a member by clicking on the IASHA e.V. button. In another framework of ideas, we would like to remind you that you can immediately submit your work to participate in our Demetrios Prizes 2019. This time we are giving you again the opportunity to participate, to show to the world your researches and Ideas, and to win 500Euros. Search title"DEMETRIOS PRIZE 2019" to see and get more information about this wonderful idea to promote and support the talent of young Students all around the world. The theses should be submitted by mail to admin@josha-archive.org until June 15, 2019.

\section{JOSHA Joumalossimene. Humanities and Arts




\section{JOSHA - Journal of Science Humanities and Arts Editorial Volume 6 Issue 2}

This year 2019 was wonderful as far as the purpose of our magazine is concerned. We were working together making visits to Schmelzeisen in Freiburg, Germany and preparing some changes in the Website. As you may have seen, now our readers are able to see the statistics with the exact number of views and downloads of every article. Moreover, we have added three buttons on the right side of the Homepage, so you can get an option to visit our links directly to the upcoming events, to our prizes, and also see how you can become a member by clicking on the IASHA e.V. button.

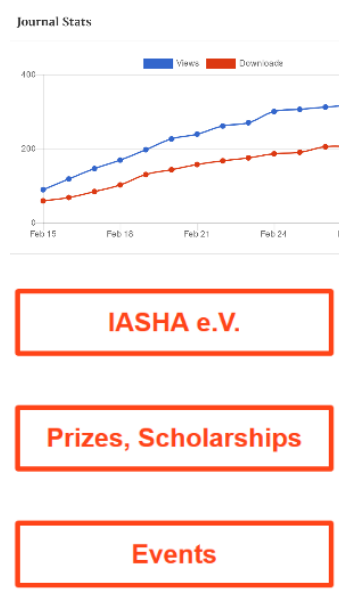

In another framework of ideas, we would like to remind you that you can immediately submit your work to participate in our Demetrios Prizes 2019. This time we are giving you again the opportunity to participate, to show to the world your researches and Ideas, and to win 500Euros. Follow the link of the title "DEMETRIOS PRIZE 2019" to see and get more information about this wonderful idea to promote and support the talent of young Students all around the world. The theses should be submitted by mail to admin@josha-archive.org until June 15, 2019. Another upcoming and very interesting event will take place on 6 July 2019 in Freiburg with the "Dai Kimoto \& his Swing Kids"! Since 2005 Dai Kimoto and his Swing Kids have been playing themselves into the hearts of the people. In the context of this concert, our team will celebrate and present the winners of the bevor mentioned DEMETRIOS PRIZE 2019. For more information about this event sponsored by the International Academy of Sciences, Humanities, and Arts (IASHA e. V.), please contact Zazie-Charlotte Pfeiffer (zaziecharlotte.pfeiffer@josha-archive.org) and Eva Senn (eva.senn@bluewin.ch) or visit the Website of the Academy (http://iasha.org/).

In the same way, we were receiving around 100 articles that confirm a total of almost 300 articles since 2014 with more than 400,000 visits and more than 300,000 downloads. Concerning this last issue, a total of 9 articles belonging to the areas of medicine, architecture and design, music, visual arts, and politics were published in February. 


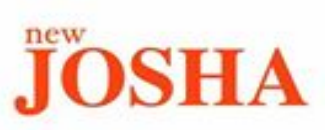

Journal of Science,

Humanities and Arts

\section{VISUAL ARTS, ARCHITECTURE, AND DESIGN}

The article „Interviewing Rainer Schmelzeisen: The Power of Light as Kinetic Art - Die Kraft des Lichts als kinetische Kunst" was the highlight of February. In the field of Visual Arts, we have brought you a wonderful interview of arts and lights with Prof. Dr. Rainer Schmelzeisen, the medical Director of Oral and Maxillofacial Surgery at the University Clinic of Freiburg in Germany and, incidentally, kinetic light artist. His works animate the viewer to position himself in front of them and thereby change his own perspective on art. We invited you to visit his homepage to see more of his creative and beautiful work at http://schmelzeisen-luxart.de/aktuelles/. From Kosovo and as well in the area of design and architecture, we present you the article ,Interactive Kinetic Architecture: Progressive Design Principles“ by Bujar Bajçinovci, Vlora Aliu, Bard Bajçinovci, and Uliks Bajçinovci. They explain to us what the coming decades are going to bring concerning the architecture in Kosovo. For example, the new interactive architecture process will continue to be largely implemented into the urbanarchitectural environment. Various performative art media also embark on interactive architectural design strategies. Therefore, the combination of sensors, processors, and effectors of the variable elements in the architectural structure transforms the perception and understanding of the architectural buildings from passive one into an active evolutive composition.

\section{MEDICINE \& BIOLOGIE}

In the area of medicine, we have shown you four different works from Colombia and Germany. The first one entitled „Association between the pulsatility index of the aortic isthmus and the cardiac function of the left ventricle in fetuses below the percentile three for the gestational age." is an article from Colombia presented by Malka Wadnipar and Juan Carlos Otero Pinto. This article covers the topic of the evaluation of the fetal circulation, mainly of the umbilical artery (AU), middle cerebral artery (MCA) and ductus venosus (DV), which have been the pillars in the diagnosis and monitoring of the main alterations in fetuses with restriction of the intrauterine growth (IUGR). Also from Colombia, Diego Armando Guzmán Abello and Cesar Augusto Abril Gaona present us the article „Functional outcomes of radial head fractures type III and IV, after management with arthroplasty or internal fixation.“. This article covers everything related to radial cup fractures, which account for $4 \%$ of anatomical fractures and aims to analyze the functional evaluation in the postoperative followup of these patients using a functional scale that gives us a perspective that favors some of these procedures. 


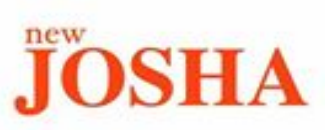

Journal of Science, Humanities and Arts

The third and fourth article in the area of medicine are both from Germany but with very different topics. The article entitled ,3D printed scaffold to monitor hanging drops on inverted microscopes“ was presented by Lukas Peintner who is showing us the design and production of a coverslip tray by conventional additive printing (3D printing) able to fit into a single well of a six-well plate to enable the observation of hanging drop spheroids using inverted microscopes. This concerns the topic of Growing cells in 3D cell culture which has become a major field in cell biology over the last decade. The last article in this field was entitled „Unraveling the syndrome of the age-associated diseases: Cancer, Cardiovascular, and Neurological Disorders. Common pathways and novel therapeutic strategies“ and was presented by Laura Faletti, Roland Mertelsmann, and Katja Zirlik also from Freiburg and cover the Cardiovascular diseases and cancer as the most frequent causes of death in the industrialized world. They explain that their incidence increases significantly with age and interestingly is also seen with a higher frequency among older people. Is there a common pathogenic mechanism underlying this triad? One possible mechanism is the age-associated mutations that occur in all the cells of the human body capable of dividing.

\section{MUSIC, LINGUISTICS \& HISTORY}

„Evaluation of GloWbE as a Tool for Big Data Corpus Linguistics“ belongs to the area of linguistics and it has been presented by Philipp Reichenbach from Germany. His article covers the interesting question about how big is the impact of the media on spoken and written language? Academic disciplines such as linguistics and digital humanities are dedicated not only to dealing with digitalization and language but also to exploring their interrelationship, opportunities, and occurring (linguistic) phenomena.

Now, in the field of Music, we bring you "If You Speak It, You Play It". This is the second part of the article with the same name presented by Ugo Rodolico, from Italy. This time the author has attached a video related to the subject, explaining more about it. The central idea of his thesis is to establish a close relationship between specific drumming technique, which is based today on the study of the rudiments seen earlier, and a more general method of learning rhythm that uses strategies and suggestions from outside classical music theory, which is understood solely as a division system. The last article of this Editorial belongs to the field of History. The articles have been being published at JOSHA within 7 chapters about the „History of the German philology in Argentina (Chapter 7 ) - GESCHICHTE DER ARGENTINISCHEN GERMANISTIK“. All of them have been presented by Lila Bujaldon de Esteves, from Argentina. This last chapter of this line of biographies and historical data is about Exil 
und Germanistik in Argentinien, more specific about German and Spanish exiled scholars of the thirties at Argentine universities.

We are happy to carry on a successful way with all your support and hope to have a wonderful 2019 overflowing with endless interesting articles from all over the world. The Editorial Board and everybody in JOSHA would like to thank our readers and authors for supporting this project. We also like to remind that you can upload a Video link to your article as well as we wish all our readers a joyful reading experience at JOSHA.

Table of content: http://josha-journal.org/en/issues

Zazie-Charlotte Pfeiffer, María Sandoval, Interviewing Rainer Schmelzeisen: The Power of Light as Kinetic Art - Die Kraft des Lichts als kinetische, Kunst

Diego Armando Guzmán Abello, Cesar Augusto Abril Gaona, Functional outcomes of radial head fractures type III and IV, after management with arthroplasty or internal fixation.

Laura Faletti, Roland Mertelsmann, Katja Zirlik, Unraveling the syndrome of age-associated diseases: Cancer, Cardiovascular, and Neurological Disorders. Common pathways and novel therapeutic strategies

Philipp Reichenbach, Evaluation of GloWbE as a Tool for Big Data Corpus Linguistics

Lila Bujaldon de Esteves, History of the German philology in Argentina (Chapter 7 ) - GESCHICHTE DER ARGENTINISCHEN GERMANISTIK

Bujar Q. Bajçinovci, Vlora Aliu, Bard Bajçinovci, Uliks Bajçinovci, Interactive Kinetic Architecture: Progressive Design Principles

Ugo Rodolico, "If You Speak It, You Play It"

Lukas Peintner, 3 D printed scaffold to monitor hanging drops on inverted microscopes

Malka M. Wadnipar, Juan Carlos Otero Pinto, ASSOCIATION BETWEEN THE PULSATILITY INDEX OF THE AORTIC ISTHMUS AND THE CARDIAC FUNCTION OF THE LEFT VENTRICLE IN FETUSES BELOW THE PERCENTILE THREE FOR THE GESTATIONAL AGE. 